\title{
Times are changing: digitalisation in child and adolescent psychotherapy
}

\author{
Katharina Allgaier ${ }^{1} \cdot$ Johanna Schmid $^{1} \cdot$ Karsten Hollmann $^{1} \cdot$ Pauline A. Reusch ${ }^{1} \cdot$ Annette Conzelmann $^{1,2}$. \\ Tobias J. Renner ${ }^{1}$
}

Published online: 31 July 2020

(c) The Author(s) 2020

Triggered by the SARS-CoV2-19 pandemic, the establishment of digital health interventions (DHI) to treat children and adolescents with psychiatric disorders has been pushed forward with an astonishing velocity. General contact restrictions forced psychotherapists to treat their patients via DHI, especially video conferences. During the first months of the pandemic, acceptance of DHI greatly improved and the extension of technical- and IT infrastructure was propelled.

DHI offer a broad spectrum of methods ranging from the augmentation of face-to-face therapy to stand-alone DHI. However, the accelerated DHI usage in psychotherapy prompts specific questions: For which groups of patients do evidence-based approaches exist? What are prerequisites and precautions? And: what are general advantages and pitfalls of DHI? This guest-editorial aims to outline the scientific state of research on DHI and to discuss practical aspects of DHI-related interventions in psychotherapy.

\section{Evidence-based DHI}

Hollis and colleagues [1] summarized 21 former meta-analyses and reviews from the beginning of the development of DHI in the 1990s until the end of 2015 in their meta-review and additionally updated a systematic review analysing 30 randomized controlled trials (RCT) using DHI. Their review represents an outstanding comprehensive approach and has recently been complemented by a systematic literature

Tobias J. Renner

Tobias.Renner@med.uni-tuebingen.de

1 Department of Child and Adolescent Psychiatry, Psychosomatics and Psychotherapy, University Hospital of Psychiatry and Psychotherapy Tübingen, Center of Mental Health Tübingen, Osianderstraße 14, 72074 Tübingen, Germany

2 Department of Psychology (Clinical Psychology II), PFH Private University of Applied Sciences, Göttingen, Germany search of our own work group [2], strictly following the criteria established in the Preferred Reporting Items for Systematic Reviews and Meta-Analyses (PRISMA) statement.

The work by Hollis and colleagues and our own search revealed that most robust evidence exists for interventions for anxiety disorders and mild to moderate depression (especially computerized cognitive behavioural therapy (cCBT) approaches).

RCT for ADHD in children and adolescents revealed rather heterogeneous results which might be explained by their highly heterogeneous approaches. The studies ranged from neurofeedback trainings to executive functioning trainings and interventions targeting everyday organization and planning skills. They show comparable (inconsistent) effects to nonpharmacological face-to-face therapy $[1,2]$.

Increasing evidence emerges for DHI targeting autism spectrum disorders which include DHI for children from preschool age to adolescence and their parents $[1,2]$. DHI for children and adolescents with ASD involve parents more frequently than DHI for other diagnoses.

Studies investigating DHI for other diagnoses such as eating disorders, psychosis, obsessive compulsive disorders, dyslexia, coordination disorders, conduct disorders with disruptive behaviour, tic disorders, insomnia or trichotillomania in children and adolescents are rather scarce. But the few available studies show promising results, though more high-quality studies are needed for a profound evaluation of DHI for those disorders.

Looking at the technical aspects, most studies use personal computers, which offer the broadest range of applications, ranging from psychoeducation in serious games or in video or written modules over training of cognitive functions to video sessions [1,2]. Smartphone usage is on the rise, allowing ambulatory assessment of mood or experience in everyday life $[1,2]$. Tablets are mainly used for trainings to improve attention or social and communicative skills via apps [1, 2]. 
Most published DHI studies were conducted in the Western Hemisphere and Asia, with only few studies from South American and African countries [2]. Due to the advantages of DHI in providing treatment over extensive distances and an increasingly evolving IT-infrastructure for example in African countries, more use of DHI can be expected worldwide.

\section{Practical aspects in using DHI}

Implementing DHI in clinical practice requires careful consideration of a variety of prerequisites and precautions [3]. Table 1 gives an overview of practical prerequisites, ranging from personal aspects over data security and regional legal frameworks to the relevance of instable therapeutic situations including suicidality. DHI provide unique benefits, as proven during the SARS-CoV2-19 lock-down, but also bring potential pitfalls. Table 2 gives an overview on aspects regarding accessibility, the implementation of interventions itself, the evidence regarding interventions as well as economic aspects [4].

In summary, DHI are promising therapeutic interventions for children and adolescents with psychiatric disorders, with already robust data regarding depression and anxiety disorders. SARS-CoV2-19 catalyses the integration of DHI into the standard repertoire of child and adolescent psychiatry and psychotherapy. Nevertheless, for using DHI in daily therapeutic work there are still challenges to overcome, ranging from technical aspects, e.g. general availability of the technical prerequisites, to the most demanding therapeutic tasks like the stabilisation of patients in acute crises. Blended treatment formats using a combination of traditional face-to-face sessions with e.g. intermittent video conferences might be the silver bullet in integrating DHI and taking advantage of their strengths.

Fortunately, at least one partner in therapy, the children and adolescents, are often accustomed to and sometimes highly trained in digitally delivered communication. So, it

Table 1 Prerequisites and precautions necessary for DHI

\begin{tabular}{|c|c|c|}
\hline Field & Aspects to consider & \\
\hline \multirow{3}{*}{$\begin{array}{l}\text { Competences of patients and } \\
\text { therapists }\end{array}$} & Personal Preferences & For specific devices/programs \\
\hline & Personal Skills & Competence to handle electronic device/software \\
\hline & Confidence & In treatment effectiveness \\
\hline \multirow[t]{3}{*}{ Data security } & Software requirements & $\begin{array}{l}\text { Use of software approved for psychotherapy by respective health care authori- } \\
\text { ties }\end{array}$ \\
\hline & & Software protects data from external access \\
\hline & Data storage & $\begin{array}{l}\text { Secure storage of patient data (including access control, encryption, and exter- } \\
\text { nal backups) in accordance with requirements of the respective health care } \\
\text { regulations }\end{array}$ \\
\hline \multirow[t]{7}{*}{ Implementation } & Legal basis & Informed consent by patients and parents \\
\hline & Environmental factors & Privacy at the patient's home \\
\hline & & $\begin{array}{l}\text { Adequate lighting (e.g. not too dark/no window in the background) to be seen } \\
\text { well over webcam }\end{array}$ \\
\hline & & Neutral background at the therapist's workplace \\
\hline & Technical aspects & Stable high speed internet connection \\
\hline & & $\begin{array}{l}\text { Webcam with high video resolution (at least in the range of Full High Defini- } \\
\text { tion }[1080 \mathrm{p}] \text { ) } \\
\text { Headset to avoid background noise }\end{array}$ \\
\hline & Therapeutic alliance & $\begin{array}{l}\text { Increased self-reflection/explanation about therapist behaviour (e.g. tell the } \\
\text { patient when taking notes and thus not looking into the camera) }\end{array}$ \\
\hline \multirow[t]{6}{*}{ At risk patients and suicidality } & Type of DHI for at risk patients & $\begin{array}{l}\text { DHI without direct contact to a therapist or only asynchronous types of com- } \\
\text { munication are inappropriate for patients with suicidal ideations. These } \\
\text { comprise the risk that the therapist does not recognize suicidal ideations that } \\
\text { would have become apparent within a personal contact }\end{array}$ \\
\hline & Warning signals & $\begin{array}{l}\text { Therapists have to be highly sensitive regarding key signals (e.g. severely } \\
\text { depressed mood, hopelessness) }\end{array}$ \\
\hline & $\begin{array}{l}\text { Interventions in case of aggra- } \\
\text { vation and safety precautions }\end{array}$ & $\begin{array}{l}\text { Increase of the frequency of synchronous communication e.g. via video confer- } \\
\text { encing as a tool to deliver support during vulnerable episodes }\end{array}$ \\
\hline & & At least one parent has to be present in the house during video therapy sessions \\
\hline & & $\begin{array}{l}\text { Therapist needs patient's/parents' contact information at hand to be able to } \\
\text { initiate emergency services when needed }\end{array}$ \\
\hline & & $\begin{array}{l}\text { Cooperation with local professionals (paediatrician, psychiatrists) for emer- } \\
\text { gency support }\end{array}$ \\
\hline
\end{tabular}




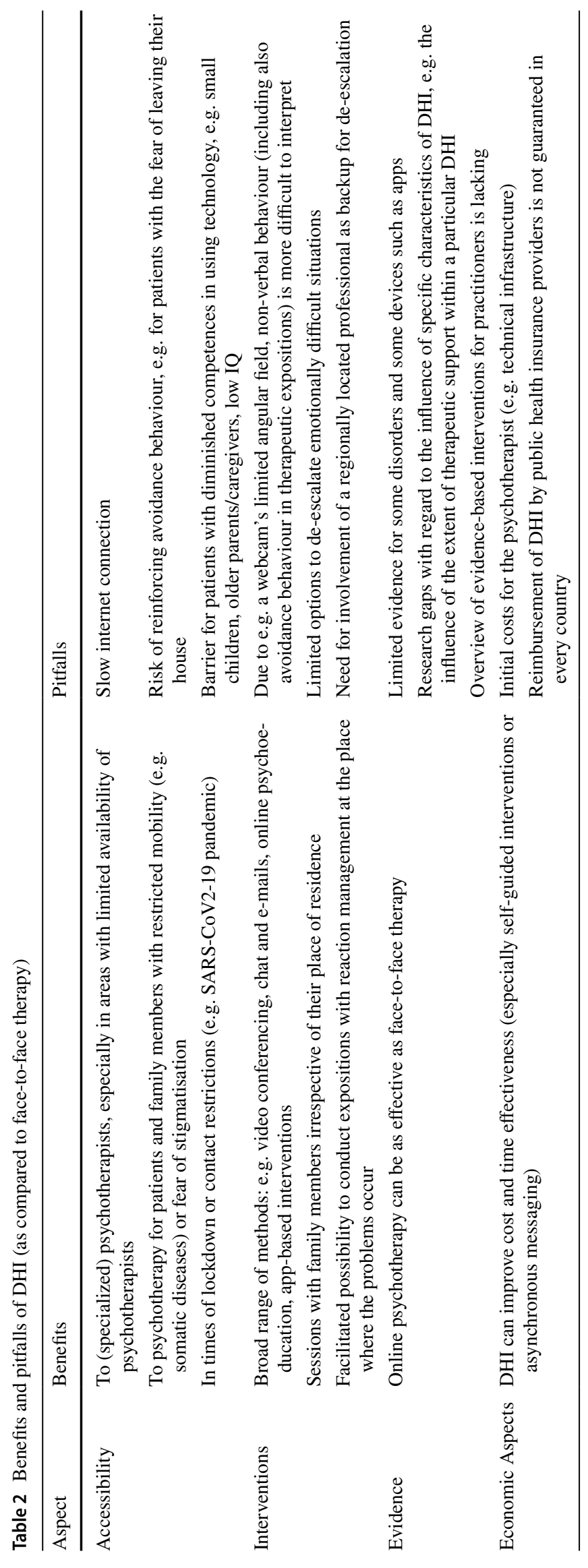


is up to us to use our profound expertise in traditional psychotherapy to create the digital pathways for reaching out to them. Times are changing. Let's go.

Acknowledgements Open Access funding provided by Projekt DEAL.

Open Access This article is licensed under a Creative Commons Attribution 4.0 International License, which permits use, sharing, adaptation, distribution and reproduction in any medium or format, as long as you give appropriate credit to the original author(s) and the source, provide a link to the Creative Commons licence, and indicate if changes were made. The images or other third party material in this article are included in the article's Creative Commons licence, unless indicated otherwise in a credit line to the material. If material is not included in the article's Creative Commons licence and your intended use is not permitted by statutory regulation or exceeds the permitted use, you will need to obtain permission directly from the copyright holder. To view a copy of this licence, visit http://creativecommons.org/licenses/by/4.0/.

\section{References}

1. Hollis C, Falconer CJ, Martin JL, Whittington C, Stockton S, Glazebrook C, Davies EB (2017) Annual research review: digital health interventions for children and young people with mental health problems - a systematic and meta-review. J Child Psychol Psychiatry 58:474-503. https://doi.org/10.1111/jcpp.12663

2. Allgaier K, Schmid J, Skarphedinsson G, Reusch PA, Ober H, Buchele I, Conzelmann A, Renner TJ (2018) The effects of human interaction on the outcomes of digital health interventions for children and adolescents with mental disorders: a systematic review and meta-analyses. Prospero. https://www.crd.york.ac.uk/prosp ero/display_record.php?ID=CRD42018103021. Accessed 11 June 2020

3. Joint Task Force for the Development of Telepsychology Guidelines for Psychologists (2013) Guidelines for the practice of telepsychology. Am Psychol 68:791-800. https://doi.org/10.1037/ a0035001

4. Stoll J, Müller JA, Trachsel M (2020) Ethical issues in online psychotherapy: a narrative review. Front Psychiatry 10:993. https ://doi.org/10.3389/fpsyt.2019.00993 